\title{
ELECTROCHEMICAL METHOD OF FRETTING CORROSION TESTING IN MODULAR HIP PROSTHESES
}

\author{
CLAUDIO T. DOS SANTOS ${ }^{1 *}$, IEDA M. V. CAMINHA ${ }^{1}$, WELLINGTON G. FERNANDES ${ }^{1}$, \\ MAURÍCIO J. MONTEIRO ${ }^{1}$, PATRÍCIA O. CUBILLOS ${ }^{2} \&$ CARLOS R. M. ROESLER $^{2}$ \\ ${ }^{1}$ National Institute of Technology (INT), Brazil \\ ${ }^{2}$ Biomechanical Engineering Laboratory, Federal University of Santa Catarina (UFSC), Brazil
}

\begin{abstract}
Modular hip prostheses allow better adjustment to the patient's anatomy. We used a combination of materials to make the prosthesis more resistant to wear and corrosion; however, modular connections are inevitably subjected to fretting corrosion, due to micromotion. Evaluation of this corrosion is generally based on two in vitro test methods: a long-term test method (fatigue-corrosion) for the simultaneous assessment of mechanical stability, particle release and analysis of damage on the surfaces of prosthesis components; and a short-term electrochemical test method, for current and potential generated by fretting and corrosion in the modular connection. In both methods, the prosthesis is mechanically loaded in a saline environment, to simulate human body conditions. Although these methods are complementary, there are still few studies using the electrochemical test method. This study aims to present the methodology used in an electrochemical test and the results obtained in our laboratory for a stainless steel commercial prosthesis. In addition, we discuss the mechanisms involved in the fretting corrosion process. We conclude that the results of the electrochemical test, together with those obtained in the fatigue-corrosion test, contribute to an effective evaluation of the quality of modular prostheses, in terms of their safety and performance.

Keywords: hip prosthesis, fretting corrosion, electrochemical test, modular interface, medical device safety, performance, head-stem combinations.
\end{abstract}

\section{INTRODUCTION}

The partial or total hip prosthesis is used to recover the function of the hip joint when functionality is lost due to the occurrence of trauma, disease or to relieve the pain resulting from a chronic inflammatory process that does not respond to conventional treatments [1].

The modular type of hip prosthesis has become widely used, because it provides a better fit to the patient's anatomy, since it is possible to combine components of different sizes, types and materials [2], [3]. Surgeons may also perform femoral head replacement on already fixed stems, for a less aggressive revision procedure [4], [5]. The head-stem modular connection of the hip prosthesis usually consists of a metal-on-metal conical junction where the femoral stem has a conical tip and the femoral head has the tapered bore for fitting, as can be seen in Fig 1.

Hip prostheses may vary from manufacturer to manufacturer, in terms of angle of the taper and bore of the head (one example can be seen in Fig. 1), tolerances, surface roughness, material, diameters of the taper and presence of "skirt" on the head [6]. Metallic materials used in these prostheses should have a set of properties, such as: good biocompatibility, mechanical strength, abrasion and corrosion resistance. The most widely used materials for manufacturing prostheses are in the AISI 316 stainless steel family, cobalt-based alloys, and titanium and its alloys.

\footnotetext{
* ORCID: https://orcid.org/0000-0002-7343-4307
} 


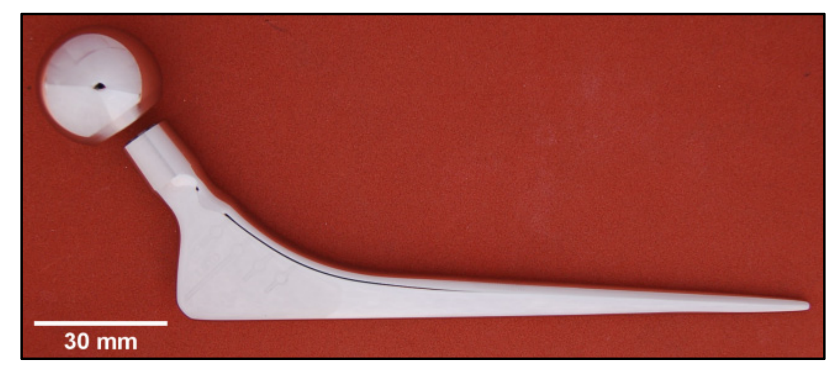

Figure 1: Hip prosthesis, head-stem modular connection. (Source: Authors, 2015 [19].)

These materials rely on the formation of a passive film that prevents the process of corrosion. The film consists of an oxide that forms spontaneously on the surface of the metal, avoiding the transport of ions and electrons [7]; however, when the components of this prosthesis are connected, they inevitably form a crevice in the connection, which can lead to so-called mechanically assisted crevice corrosion or fretting corrosion, a corrosion process that occurs due to the formation of crevices combined with the fretting in the interfaces that are submitted to small-scale relative motion [4], [6]. This corrosion is related to the combined action of the mechanical removal of the passive film due to fretting, and corrosion of the exposed metal surface with the consequent release of debris, as seen in the Fig. 2 example. It is not yet clear which design, material or surface modifications can minimize or eliminate the fretting corrosion without the need to eliminate the modular connection itself.
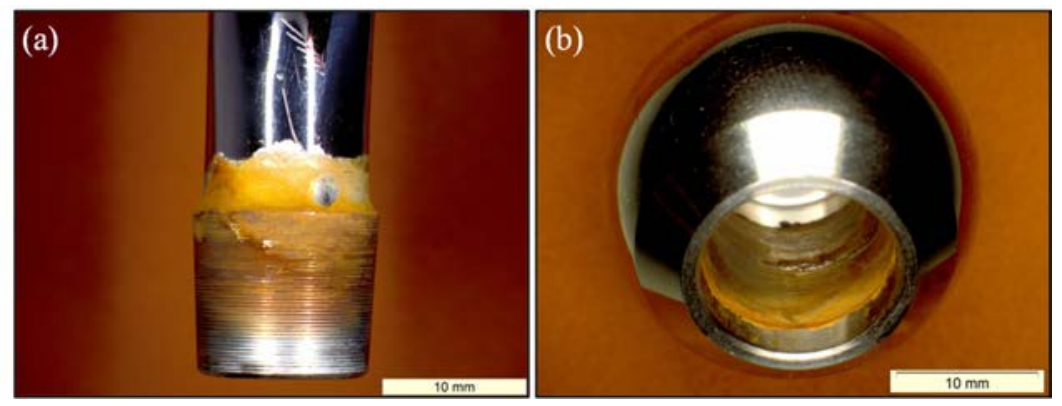

Figure 2: Corrosion in the trunnion (a) and head (b) of a stainless steel hip prosthesis, after long-term fatigue-corrosion test (107 cycles) in an aqueous $0.90 \% \mathrm{NaCl}$ solution. (Source: Authors, 2015 [19].)

Corrosion of a metal prosthesis in the human body is undesirable for two main reasons: it can reduce the structural integrity of the prosthesis; and the release of ions and particles usually causes chronic allergies, inflammatory reactions or other toxic reactions in the body, which can lead to the need for revision surgery, thus increasing patient suffering and treatment costs [2]. The revision surgery may have double the cost of the primary surgery, due to the complications associated with the fixation of the material and the bone quality of the patient [8], [9]. Ideally, the release of ions and particles should be maintained at a satisfactory low level over the time in service, which is estimated at 15 or 20 years, depending on the material [10]. 
The analysis of the fretting corrosion of hip prostheses is extremely important, in order to evaluate their propensity to release ions and particles into the modular interfaces, allowing the comparison of prostheses with different characteristics, such as different manufacturers, designs, surface finishes and combinations of materials for the head and the stem. This analysis is usually performed by means of a short-term test using an electrochemically simulated corrosion chamber. According to a recent study [4], there are still few data in the literature that were obtained using electrochemical chambers, with most of the information pertinent to fretting corrosion damages based on retrieval studies [4], [11]-[13].

It is possible to detect the corrosion not only in the interface of the head-taper, but also in other regions of the prosthesis that are subject to the relative movement. The great advantage of this method is the possibility of real-time evaluation of the effect of compressive loads on the current generated at the head-taper interface in a controlled environment [4].

The purpose of this study is to present the electrochemical method used in the fretting corrosion test of modular hip prostheses and provide the results obtained in our laboratory for a commercial prosthesis. The results are discussed in terms of the mechanisms proposed in the literature for this corrosion process. At the end of the study, the importance of the electrochemical test, together with the fatigue-corrosion test, is highlighted for obtaining an evaluation of the quality of the prostheses.

\section{MATERIALS AND THE METHOD OF ELECTROCHEMICAL TESTING}

Our electrochemical chamber consists of a cylindrical acrylic vat filled with $1 \mathrm{~L}$ of $0.90 \%$ $\mathrm{NaCl}$ aqueous solution (Alphatec, 99.5\%) containing the reference electrode $(\mathrm{Ag} / \mathrm{AgCl}$, Analion, R-684), the working electrode (WE), which in this case is the hip prosthesis, and a counter electrode (CE) of the same material as the prosthesis (Fig. 3). The apparatus was assembled in accordance with the recommendations of ASTM F1875:2014 [14]. The saline solution used in the test is called an artificial physiological environment, because it seeks to simulate the aggressive effect within the human body.

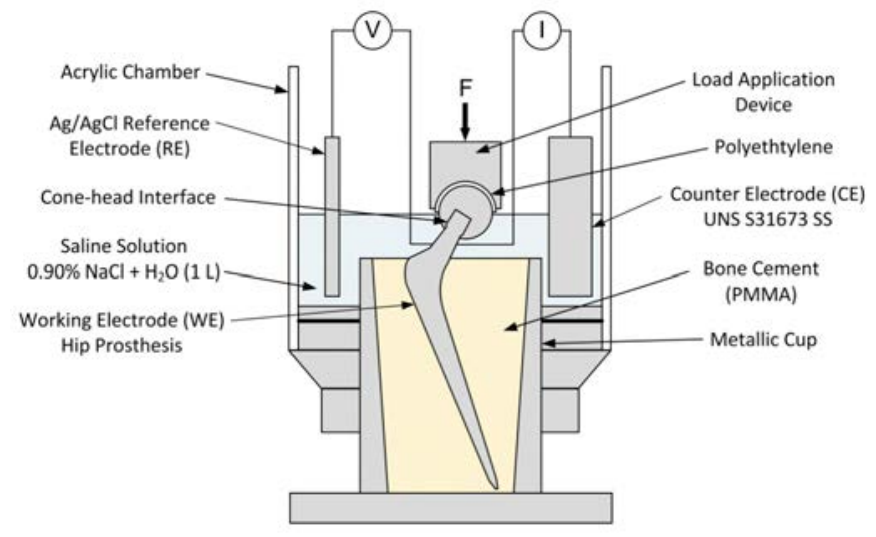

Figure 3: Schematic drawing of the electrochemical chamber for fretting corrosion testing of the head-taper connection of hip prostheses.

To perform the tests, the modular head was fitted to the stem with a load of $-2000.0 \mathrm{~N}$ at a displacement rate of $0.05 \mathrm{~mm} / \mathrm{s}$, as recommended by ASTM F2009: 2011 [15]. For this, we used the Instron uniaxial mechanical testing machine, Model 3382. The head assembly is 
performed after prior wetting of the surfaces of the connection with the test solution, thus simulating the "worst-case" condition, whereby the aggressive environment penetrates into the cone gap during the service period, contributing to the process of corrosion.

To position and support the prosthesis for the application of cyclical mechanical loading of the prosthesis is obtained by embedding in polymethylmethacrylate bone cement (PMMA, Baumer). The prosthesis was embedded in an anatomical position, according to ISO 7206-6: 2013 [16], with angles $\alpha=10^{\circ}$ and $\beta=9^{\circ}$. Then, the chamber is mounted on the mechanical loading system of the dynamic test machine (Fig. 4). In this case, the Instron servo-hydraulics machine (model 8872), was used with a load cell of $25.0 \mathrm{kN}$.

The head of the prosthesis was mechanically loaded by means of a loading device with a semi-spherical surface of ultra-high molecular weight polyethylene (UHMWPE). The loading device has a ball bearing to enable lateral movement due to deformation of the prosthesis during the test. This measurement system permits the performance of tests with different levels of cyclic load and different oscillation frequencies, allowing the evaluation of the effect of these parameters on the fretting corrosion rate.

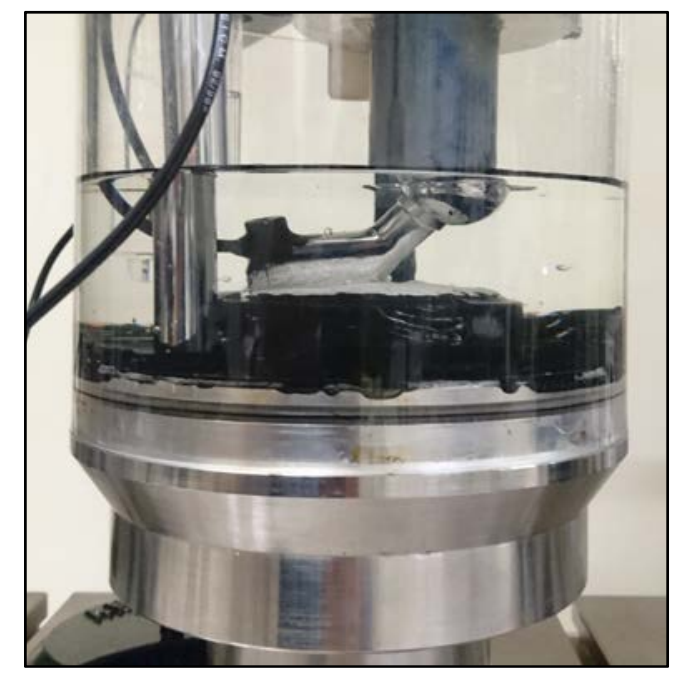

Figure 4: Electrochemical chamber mounted on the servo-hydraulic machine and the load application device.

For monitoring potential (OCP) and current of the prosthesis during the test, generally a potentiostat is used, connected to a computer dedicated to the data acquisition. In our study, we used the Metrohm Autolab potentiostat, model PGSTAT302N. For the OCP reading, the electrochemical noise module $(\mathrm{ECN})$ of this potentiostat was used. The tests were performed at room temperature $\left(\sim 25^{\circ} \mathrm{C}\right)$ and the $\mathrm{pH}$ of the solution was measured at the beginning and at the end of the test: $\mathrm{pH}$ was maintained between 6 and 7 in all tests performed. The prosthesis was kept at rest for at least 1 hour prior to mechanical loading, to stabilize the potential and current reading.

We show examples of the results obtained using this apparatus on a UNS S31673 stainless steel hip prosthesis (stem-head pair similar to that of Fig. 1), composed of a $150 \mathrm{~mm}$ polished stem, 12/14 taper and a head diameter of $28 \mathrm{~mm}$. Results were obtained with the application of a sinusoidal cyclic load with a minimum value of $-2300.0 \mathrm{~N}$, maximum of $-230.0 \mathrm{~N}(\mathrm{R}=$ 
10) and a frequency of $1.0 \mathrm{~Hz}$, according to ISO 7206-6: 2013 [16]. It is important to highlight that this is still the type of prosthesis that is most used in Brazil, due to the low cost and satisfactory properties of steel. Table 1 shows the nominal composition of UNS S31673 steel (AISI 316LVM) [17].

Table 1: Nominal composition (weight\%) of UNS S31673 stainless steel [17].

\begin{tabular}{|c|c|c|c|c|}
\hline Carbon (C) & Silica (Si) & Manganese (Mn) & Nickel (Ni) & Chromium (Cr) \\
\hline 0.030 max. & 0.75 max. & 2.00 max. & $13.00-15.00$ & $17.00-19.00$ \\
\hline Mo & Sulphur $(\mathrm{S})$ & $\mathrm{P}$ & Copper $(\mathrm{Cu})$ & $\mathrm{N}$ \\
\hline $2.25-3.00$ & 0.010 max. & 0.025 max. & 0.50 max. & 0.10 max. \\
\hline
\end{tabular}

Note: The balance is Iron $(\mathrm{Fe})$.

\section{RESULTS AND DISCUSSION OF ASSOCIATED MECHANISMS}

The results of the fretting corrosion test of the UNS S31673 (AISI 316LVM) stainless steel hip prosthesis are shown in Fig. 5.

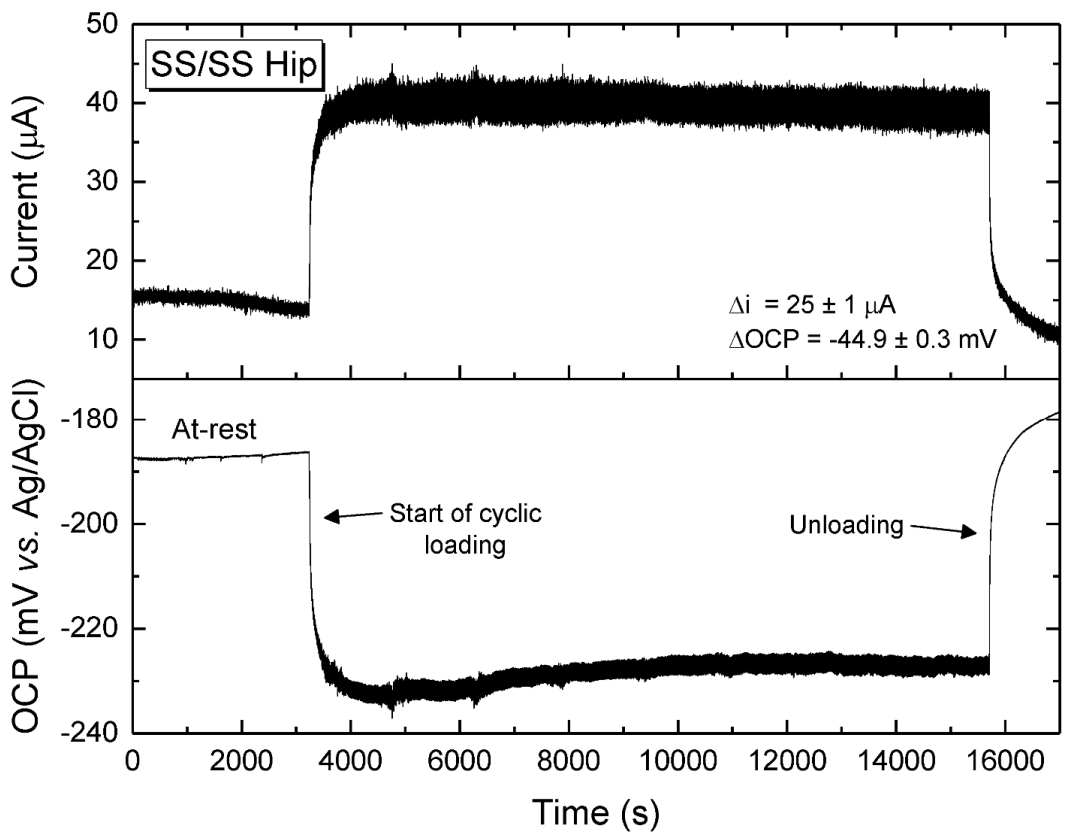

Figure 5: Current (top) and potential (bottom) profiles of the UNS S31673 stainless steel prosthesis, obtained before and after cyclic mechanical loading of -230.0 to $-2300.0 \mathrm{~N}, \mathrm{f}=1.0 \mathrm{~Hz}$.

With the start of cyclic loading, it is possible to observe an abrupt displacement in the curves of current and OCP. This displacement indicates the onset of fretting corrosion, which is the combined action of passive film abrasion and chemical changes within the crevice formed in the head-taper connection. 
According to the mechanism described in [6], mechanical loading induces high shear and compression stresses on the taper and head surfaces, which are sufficient to break the passive film. With the load cycling, the film becomes constantly broken by the fretting process. The rupture of the film exposes the metal directly to the aggressive medium, causing its ionic dissolution: $\left(\mathrm{M} \rightarrow \mathrm{Mn}^{+}+n e ́\right)$. On the other hand, high driving force for the formation of passive oxide film induces the hydrolysis of the aqueous solution according to the following equation.: $\mathrm{M}+\mathrm{H}_{2} \mathrm{O} \rightarrow \mathrm{MO}+2 \mathrm{H}^{+}+2$ é [6].

These two processes generate electrons and change the potential of the prosthesis, causing the observed displacements [6]. The increase in current with fretting is due to the potential difference that is created between the prosthesis that is suffering fretting and the counter electrode at rest. Fig. 6 illustrates the ionic dissolution and repassivation processes that occur after the oxide layer rupture.

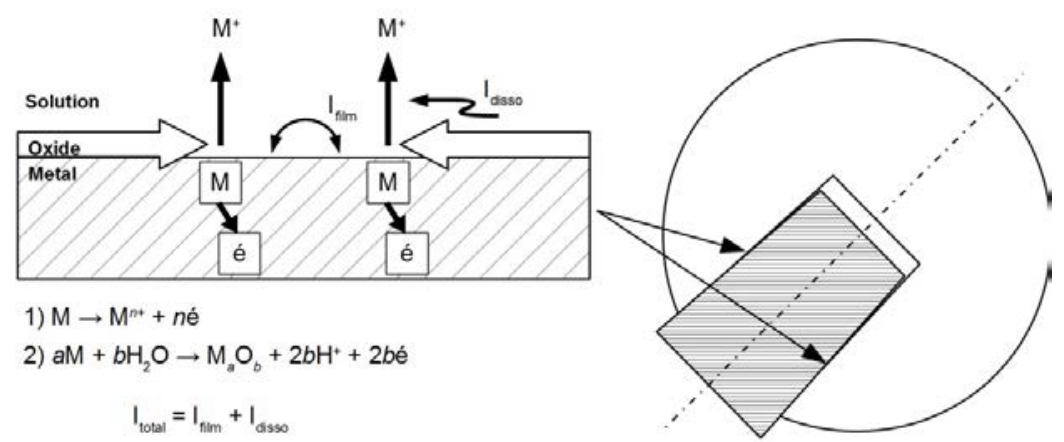

Figure 6: Schematic drawing that shows the repassivation reaction after the rupture of the oxide film and the ionic dissolution reaction (left); and the region of the connection where mechanically assisted crevice corrosion (fretting corrosion) occurs (right). (Source: Adapted from Gilbert and Jacobs [6] and Hussenbocus et al. [18].)

In fretting corrosion, the fluid enters the crevice and the crevice itself contributes to modify the chemical composition of the medium (increase of chloride ions $\left[\mathrm{Cl}^{-}\right]$and local reduction of $\mathrm{pH}$ ), as in crevice corrosion; however, for alloys which form a passive oxide layer such as stainless steel, this change in composition of the confined fluid is not sufficient for the corrosion process to continue, because the oxide layer prevents the dissolution of the metal. With the contribution of the fretting caused by the small-scale cyclic movement, the corrosion process becomes continuous, which is evidenced by the displacement observed in the current and OCP curves. According to Gilbert and Jacobs [6], as the fretting makes the potential more negative, it may have the effect of reducing the thickness and stability of the oxide layer that reforms on the surface of the entire prosthesis. Consequently, the oxide film becomes less able to withstand corrosive attack, resulting in large-scale corrosion and localized corrosion, which are generally evidenced by observations in retrieved implants.

Fig. 7 shows the magnified profile of current, load and OCP curves at the end of the test shown in Fig. 5. Note that there is a periodic oscillation with a frequency of $1 \mathrm{~Hz}$ in the curves, which corresponds to the frequency of mechanical loading, indicating that it has a direct influence on current and potential behavior. This behavior is indicative of the continuous process of breakdown and repassivation of the oxide film. 


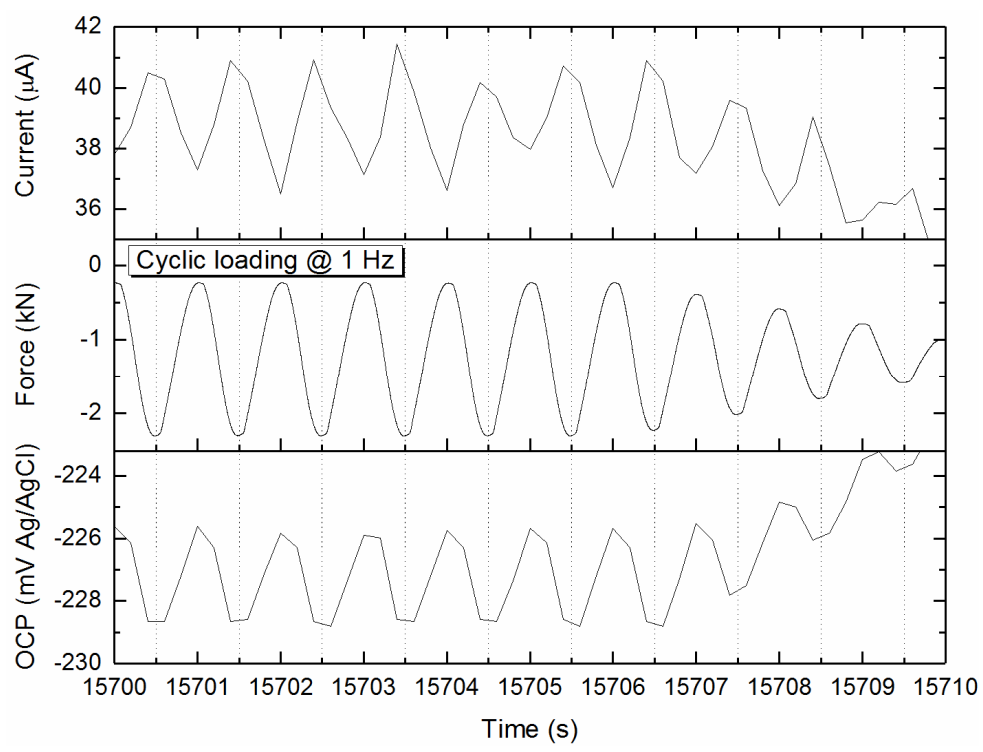

Figure 7: Magnification of the current (top) and potential (bottom) profiles at the end of the mechanical loading (middle). Note the change in current and potential behavior with the gradual onset of unloading.

The average current and potential in the initial resting regime were $14.8 \pm 0.5 \mu \mathrm{A}$ and $-187.0 \pm 0.2 \mathrm{mV}$, respectively. On the other hand, in the mechanical loading regime, the root mean square (RMS) values of current and potential were $40.1 \pm 0.9 \mu \mathrm{A}$ and $-231.9 \pm 0.2$ $\mathrm{mV}$, respectively. Current and potential have opposite profiles, which means that when the potential is at its minimum the current is at its maximum, while the profile of the potential is similar to that of mechanical load, which means that when the load reaches its minimum value $\left(\mathrm{F}_{\min }=-2300 \mathrm{~N}\right)$, the potential is also minimal, while at this point the current is at its maximum.

The results of the electrochemical fretting corrosion test are important for understanding the effect of design changes, load application modes, and combination of components made from different materials. Recently, use of electrochemical tests by Rowan et al. [4] evaluated the effect of two different designs (V40 and 12/14) of titanium alloy taper and two different head materials (Co-Cr and ceramic) on the fretting corrosion. They showed that the V40 taper with ceramic head presented the lowest propensity to fretting corrosion than the same taper with a Co-Cr head. While in the 12/14 taper design, the ceramic and Co-Cr heads exhibited similar behavior, indicating that design also has an influence on fretting corrosion. In another recent study using a similar methodology, Panagiotidou et al. [12] examined fretting corrosion in several head-stem combinations as a function of the frictional torque and bending moment. They showed that the Co-Cr tapers presented the lowest current, when combined with a ceramic head.

Although the electrochemical test helps to identify the fretting corrosion, the use of complementary techniques is essential for a more effective assessment of this corrosion process. Analysis of chemical composition, microstructure, surface damage, roughness and disassembly force of head are fundamental actions for a more complete characterization and understanding of the differences in electrochemical behavior between the prostheses. 
It is important to highlight that when the prostheses have good performance and safety, they improve the quality of life of the implanted patient and reduce the risk of rejection during the time in service, besides reducing the high hospital expenses associated with the purchase of a new prosthesis, revision surgeries and medical treatment.

\section{CONCLUSION}

The electrochemical method proved to be fast and efficient for the evaluation of fretting corrosion of modular hip prostheses. Results of this test, together with those obtained in the fatigue-corrosion test, allow for a consistent evaluation of the quality of modular prostheses, in terms of their mechanical and electrochemical safety and performance.

\section{ACKNOWLEDGEMENTS}

We are grateful to Metrohm do Brasil and its specialists Jonas Motte Nogueira, André Guimarães de Oliveira, Paula Gimenes Machado and Vinícius Santos for technical support. Thanks to Jeremy L. Gilbert of Clemson University (MUSC) and Ivan Bastos (UERJ) for information that contributed to the assembly and testing of our measurement system. Thanks to Javier A. Carreno Velasco and Rodrigo Vieira Landim (INT/ $\left.\mathrm{LAH}_{2} \mathrm{~S}\right)$ for their suggestions and help in the preparation of the method. Also, thanks to Jorge A. Hinostroza Medina (INT/LACPM) for contributing to this work.

\section{REFERENCES}

[1] Simioni, S., Manual da Qualidade de Implante em Artroplastia de Quadril [Manual of Quality of Arthroplasty Implants] (In Portuguese), 1st ed., Curitiba: Champagnat, p. 106, 2012.

[2] Urban, R. et al., Characterization of solid products of corrosion generated by modularhead femoral stems of different designs and materials. Modularity of Orthopedic Implants, ASTM International: West Conshohocken, PA, p. 33, 1997.

[3] Brown, S., Abera, A., D'Onofrio, M. \& Flemming, C., Effects of neck extension, coverage, and frequency on the fretting corrosion of modular THR bore and cone interface. Modularity of Orthopedic Implants, ASTM International: West Conshohocken, PA, pp. 189-198, 1997.

[4] Rowan, F.E., Wach, A., Wright, T.M. \& Padgett, D.E., The onset of fretting at the head-stem connection in hip arthroplasty is affected by head material and trunnion design under simulated corrosion conditions. J Orthop Res, 36(6), pp. 1630-1636, 2018.

[5] De Thomasson, E., Conso, C. \& Mazel, C., A well-fixed femoral stem facing a failed acetabular component: To exchange or not? A 5- to 15-year follow-up study. Orthop Traumatol Surg Res, 98(1), pp. 24-29, 2012.

[6] Gilbert, J. \& Jacobs, J., The mechanical and electrochemical processes associated with taper fretting crevice corrosion: A review. Modularity of Orthopedic Implants, ASTM International: West Conshohocken, PA, p. 15-45, 1997. Available from: https://www.astm.org/DIGITAL_LIBRARY/STP/PAGES/STP12020S.htm.

[7] Cohen, J., Current concepts review. Corrosion of metal orthopaedic implants. J Bone Joint Surg Am, 80(10), p. 1554, 1998.

[8] Rodrigues, C.V.M., Próteses Totais de Quadril: Diagnóstico do Panorama Nacional e Elaboração de Diretrizes para as Políticas Públicas. Universidade Federal do Rio de Janeiro, 2006.

[9] Arndt, Â.B.M., Telles, J.L. \& Kowalski, S.C., O custo direto da fratura de fêmur por quedas em pessoas idosas: análise no setor privado de saúde na cidade de Brasília, 
2009 [The direct cost of femur fracture for...: analysis in the private sector in the city of Brasilia, for 2009]. Rev Bras Geriatr e Gerontol, 14(2), pp. 221-231, 2011.

[10] Chen, Q. \& Thouas, G.A., Metallic implant biomaterials. Mater Sci Eng R Reports, 87, pp. 1-57, 2015.

[11] Goldberg, J.R. \& Gilbert, J.L., In vitro corrosion testing of modular hip tapers. $J$ Biomed Mater Res, 64B(2), pp. 78-93, 2003.

[12] Panagiotidou, A. et al., The effect of frictional torque and bending moment on corrosion at the taper interface. Bone Joint J, 97B(4), pp. 463-472, 2015.

[13] Dos Santos, C.T., Barbosa, C., Monteiro, de J.M., Abud, I.C., Caminha, I.M.V. \& Roesler, C.R.M., Characterization of the fretting corrosion behavior, surface and debris from head-taper interface of two different modular hip prostheses. $J$ Mech Behav Biomed Mater, 62, pp. 71-82, 2016.

[14] ASTM F1875-98(2014), Standard Practice for Fretting Corrosion Testing of Modular Implant Interfaces : Hip Femoral Head-Bore and Cone Taper Interface, vol. i, ASTM International: West Conshohocken, PA, pp. 1-6, 2014.

[15] ASTM F2009-00, Standard Test Method for Determining the Axial Disassembly Force of Taper Connections of Modular Prostheses, ASTM International: West Conshohocken, PA, pp. 1-4, 2011.

[16] ISO 7206-6:2013. Implants for surgery. Partial and total hip joint prostheses. Part 6: Endurance properties testing and performance requirements of neck region of stemmed femoral components. ISO Web Site, 2013. www.iso.org/standard/51186.html. Accessed on 28 Mar. 2019.

[17] ASTM International, ASTM F138-13a. Standard Specification for Wrought 18Chromium-14Nickel-2.5Molybdenum Stainless Steel Bar and Wire for Surgical Implants (UNS S31673), ASTM International, pp. 1-5, 2013.

[18] Hussenbocus, S., Kosuge, D., Solomon, L.B., Howie, D.W. \& Oskouei, R.H., HeadNeck Taper Corrosion in Hip Arthroplasty, pp. 18-21, 2015.

[19] Dos Santos, C.T., Caminha, I.M.V., Fernandes, W.G., Monteiro, M.J., Cubillos, P.O. \& Roesler, C.R.M., Evaluation of the technology of national and imported orthopedic prostheses used in total hip arthroplasty. Report for and funded by Brazilian Ministry of Health, 2015. 